\title{
Molecular Beacons: Powerful Tools for Imaging RNA in Living Cells
}

\author{
Ricardo Monroy-Contreras and Luis Vaca \\ Instituto de Fisiología Celular, Universidad Nacional Autónoma de México, 04510 Mexico, DF, Mexico \\ Correspondence should be addressed to Luis Vaca, lvaca@ifc.unam.mx
}

Received 9 November 2010; Revised 14 June 2011; Accepted 22 June 2011

Academic Editor: Dmitry A. Stetsenko

Copyright ( $) 2011$ R. Monroy-Contreras and L. Vaca. This is an open access article distributed under the Creative Commons Attribution License, which permits unrestricted use, distribution, and reproduction in any medium, provided the original work is properly cited.

\begin{abstract}
Recent advances in RNA functional studies highlights the pivotal role of these molecules in cell physiology. Diverse methods have been implemented to measure the expression levels of various RNA species, using either purified RNA or fixed cells. Despite the fact that fixed cells offer the possibility to observe the spatial distribution of RNA, assays with capability to real-time monitoring RNA transport into living cells are needed to further understand the role of RNA dynamics in cellular functions. Molecular beacons (MBs) are stem-loop hairpin-structured oligonucleotides equipped with a fluorescence quencher at one end and a fluorescent dye (also called reporter or fluorophore) at the opposite end. This structure permits that MB in the absence of their target complementary sequence do not fluoresce. Upon binding to targets, MBs emit fluorescence, due to the spatial separation of the quencher and the reporter. Molecular beacons are promising probes for the development of RNA imaging techniques; nevertheless much work remains to be done in order to obtain a robust technology for imaging various RNA molecules together in real time and in living cells. The present work concentrates on the different requirements needed to use successfully MB for cellular studies, summarizing recent advances in this area.
\end{abstract}

\section{Introduction}

A wealth of experimental evidence accumulated to this date illustrates the wide range of cellular functions conducted by ribonucleic acids (RNAs). In many occasions these functions involve RNA transport from one cellular compartment to another or into the same compartment to specialized regions. In order to accomplish this, RNA molecules are under a specific and selective control via expression levels and/or stability in a spatial-temporal manner. Different methods developed to purify RNA [1-3] from cell populations or tissues have provided relevant information about the relative concentration of RNA in cells, or cellular compartments, yet these methods provide limited information about the spatial-temporal distribution of RNAs and their dynamic transport.

The integral understanding of cellular process in which RNA is involved, requires a method that reveals RNA localization in real time in a subcellular context in living cells. The information obtained from this type of assays promise to impulse the advancement in molecular biology, medical research, and diagnostics.

Many methods have been developed to measure RNA expression levels between different cell populations, such as the polymerase chain reaction (PCR) [4], northern blot [5], serial analysis of the gene expression (SAGE) [6], suppression of subtractive hybridization (SSH) [7], differential display [8], representational difference analysis (RDA) [9], expressed sequence tag (EST) [10], and microarrays [11]. Thus these techniques in addition to databases containing genomic data for a wide variety of biological entities, supply a useful instrument for understanding physiology or pathology at the molecular level. Nevertheless, none of the techniques previously mentioned could provide information about the subcellular RNA localization and its transport.

Through the use of fluorescent in situ hybridization assays [12], scientists have identified gradients of RNA in cells [13], embryos [14], and tissues [15, 16]. However this technique is conducted on fixed samples and therefore provides limited information about the dynamics of such 
gradients. Other disadvantages are the laborious and timeconsuming nature of the assay, the difficulty that involves the analysis of the images and variations due to handling different trials. The chemicals used for dehydration and fixation could affect the signal level [17] and alter the integrity of organelles, hampering any conclusions about spatial changes in organelles or compartments.

The most adequate procedure to obtain spatial-temporal resolution of the RNA dynamics is using living cell assays. Under these conditions, the probes to be used must have high specificity, sensitivity, and good signal to background ratio, especially for low abundance RNA molecules. Ideally, the experimental procedure should be able to detect discrete changes in RNA concentrations of the sample. Furthermore, a robust method should provide additional information like single nucleotide mutations, deletions, insertions, and single nucleotide polymorphisms (SNPs). Another fact to take in consideration is the method for intracellular delivery; it should not produce the degradation of the probe or damage the cell. Finally, the probes utilized should have fast kinetics of hybridization with its target at room temperature, in order to be useful in real-time measurements.

Recent advances in DNA chemistry deliver promising nanostructured probes known as molecular beacons (MB), which may fulfill many (if not all) of the requirements highlighted above. MBs are slowly becoming powerful tools to explore RNA function and dynamics in living cells. Combined with advanced imaging techniques, $\mathrm{MB}$ are delivering interesting and sometimes surprising results about RNA dynamics in living cells and tissues.

A recent work reviews different forms of linear and nonlinear probes useful for cell imaging studies [18]. In this review we will address the use of MBs for RNA imaging in living cells, analyzing some of the key features required for successful MB design. We will review also various delivery methods commonly used for $\mathrm{MB}$ introduction into living cells.

\section{Structure and Function of Molecular Beacons}

MBs are oligonucleotide probes that fluoresce upon hybridization with its targets [20]. To build a MB, an oligonucleotide chain is linked covalently to a fluorescent dye (reporter) usually at $5^{\prime}$ end and to a fluorescence quencher at the opposite end. The probes have the capability to produce a stem-loop hairpin structural conformation in absence of its target, due to complementary sequences from 5 to 7 nucleotides in length, located at the termini of the molecule (Figure 1(a)). The resulting secondary structure of the MB brings together the reporter and the quencher, making possible the energy transfer, which produces fluorescence quenching. When $\mathrm{MB}$ hybridizes to its target, the reporter and quencher are separated $(\geq 10 \mathrm{~nm})$, preventing the quenching of the fluorescence from the reporter (Figure $1(\mathrm{~b})$ ).

Most MB studies have been carried out using nucleic acids in in vitro assays. In fact, several real-time PCR strategies involve the use of $\mathrm{MB}$ for monitoring sample amplification [21-25]. Such strategies involve heating of the solution to high degrees in order to maximize MB-target association.
Unfortunately, heating to high temperatures cannot be conducted when studying living cells, and therefore MB design should account for MB-target association at physiological temperature.

We have found that a careful design of the MB stem sequence is essential for MB-target association at physiological temperature ranging from 20 to 37 degrees centigrade.

In a solution of $\mathrm{MB}$ containing an excess of target ( $\geq$ fivefold $\mathrm{MB}$ concentration) it is possible to observe an increment in fluorescence intensity between 10- and 200-fold [20] in comparison with a solution without a target (Figure $1(\mathrm{c})$ ). When target concentration is unknown (like in the case of nucleic acids detection in living cells) it is desirable to have fast hybridization rates and improved signal to background ratio, especially when the target is a nucleic acid present in a low concentration. Some MB design strategies have been implemented recently to address this issue.

MB shows an increased specificity in comparison to linear probes having an equal number of complementary nucleotides with its target; this is due to competition between the stem-loop hairpin structure and the MB-target hybridized state [26]. This phenomenon gives the capability to the MB to discriminate between perfectly matched and single mismatched targets. To reach this high specificity an appropriate $\mathrm{MB}$ design is required, taking into consideration the experimental conditions, such as magnesium concentration, ionic strength, and temperature.

We have found that prior to living cell studies, it is highly advisable to conduct hybridization and thermal denaturing assays using a spectrofluorometer and a real-time thermal cycler, respectably. In order to have a prediction about the $\mathrm{MB}$ behavior in living cells assays it is recommended to calculate the thermodynamical parameters of the hybridization kinetics, that is, changes in enthalpy and entropy, melting temperature, also association and dissociation constants of a specific MB-target pair using the thermal profile obtained from the thermal denaturing and parameters obtained from the hybridization assays. See [26, 27] for detailed protocols.

Molecular beacons have been used successfully in a wide variety of applications due to its high signal to background ratio, including qPCR [21-25], SNPs detection by real-time PCR [28-31], genotyping [32-36], mutation detection [37$39]$, assaying for nucleic acid cleavage [40, 41], cancer-cell detection [42-44], monitoring viral infection [45-47], and RNA expression, transport, and localization in living cells [48-51].

\section{Designing Molecular Beacons}

Three key factors must be considered for MB design, the efficiency of the quenching, the stem-loop secondary structure formed by the sequences at the $\mathrm{MB}$ termini and the $\mathrm{C}-\mathrm{G}$ content of the stem (specially relevant for assays conducted at physiological temperatures).

3.1. Reporter and Quencher: Mechanism and Pair Election. $\mathrm{MB}$ use a reporter-quencher pair to build a signal transduction system $[52,53]$. The quenching that takes place when 


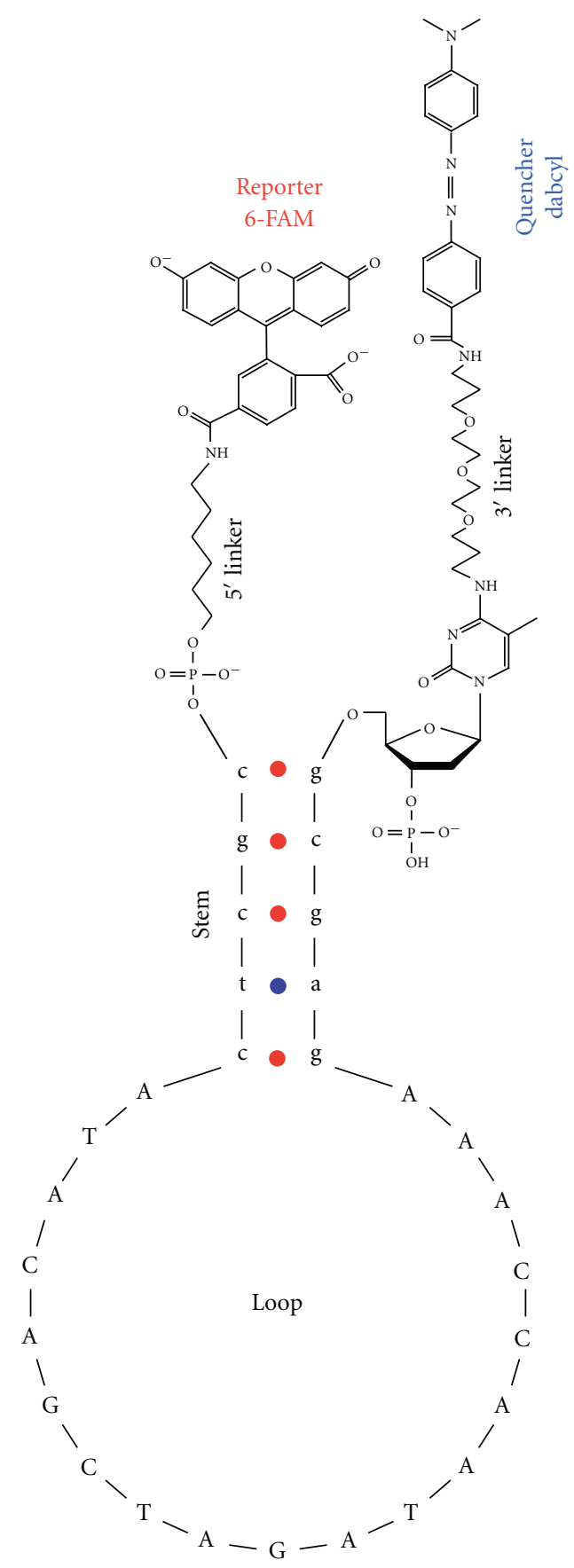

(a)

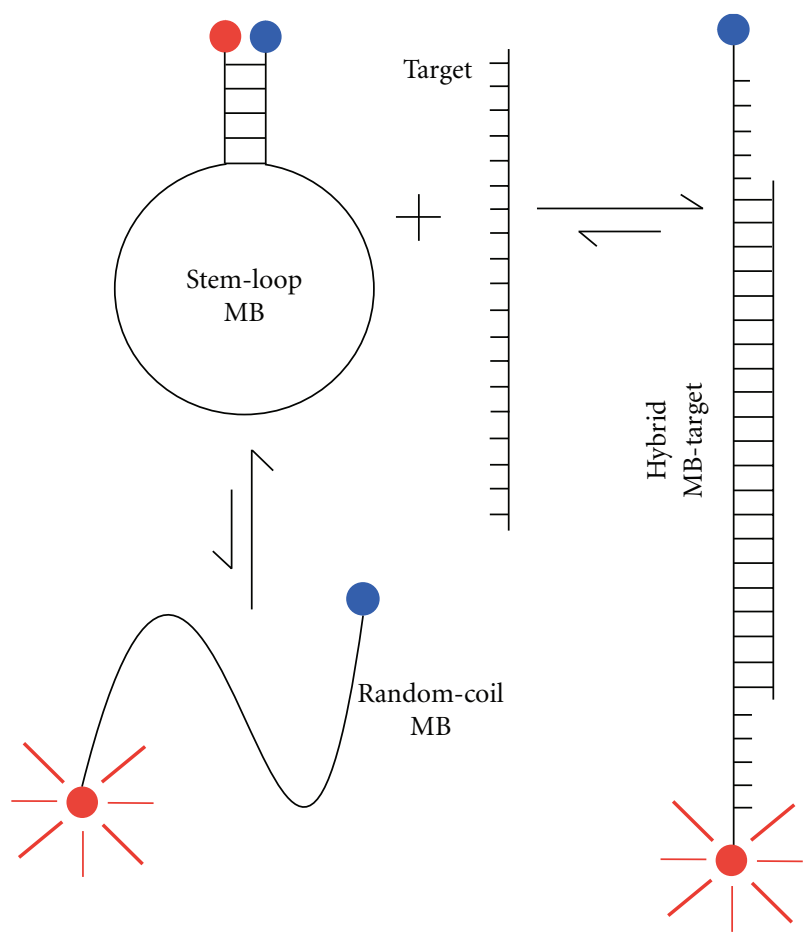

(b)

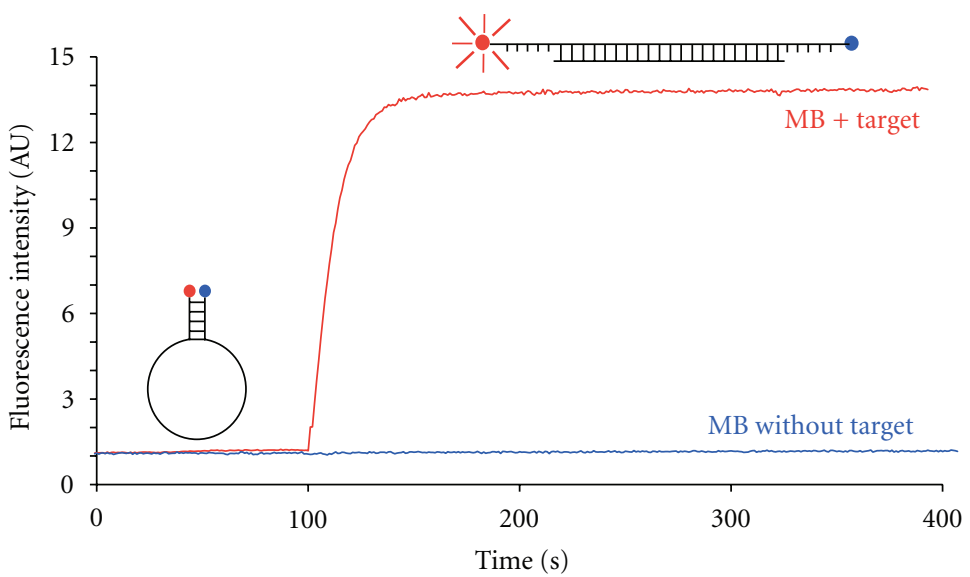

(c)

FIGURE 1: Structure and function of MB. (a) Stem-loop hairpin structure of a MB showing its four structural components: loop, stem, quencher, and reporter. The chemical structure of the linkers is drawn according to the manufacturer (Integrated DNA Technologies, Iowa, USA). (b) Mechanism of MB function. A MB in a solution containing both MB and target could be in three states: free in a stem-loop hairpin conformation, hybridized with it target, or unbound in a random-coil conformation. The random-coil conformation of the MB contributes to the background. (c) Fluorescence intensity. The blue line shows the fluorescence intensity for a MB in solution (50 nM) during $400 \mathrm{~seconds}$ (background), and the red line corresponds to the addition (100 seconds) of a target oligonucleotide ( $500 \mathrm{nM}$ ) that hybridize the MB at the loop region. An increase in fluorescent intensity of approximately thirteenfold is observed. The reporter is represented with a red circle and the quencher with a blue. UA means arbitrary units. 
TABLE 1: Reporter-quencher pairs. For every one reporter is showed the peak of excitation, emission, and also the quenchers that could be used for observing a high quenching efficiency. The excitation peak and emission peak values were obtained from reference [58].

\begin{tabular}{lccc}
\hline Reporter & Excitation peak $(\mathrm{nm})$ & Emission peak $(\mathrm{nm})$ & Compatible quenchers \\
\hline Cy3 & 550 & 605 & BHQ-2 and Dabcyl \\
Cy5 & 640 & 675 & BHQ-3 and Dabcyl \\
CR-6G & 505 & 570 & Dabcyl \\
6-FAM & 484 & 525 & Iowa Black-FQ, BHQ-1 and Dabcyl \\
HEX & 525 & 554 & BHQ-1, Iowa Black-FQ and Dabcyl \\
TAMRA & 555 & 605 & Dabcyl \\
TET & 490 & 535 & BHQ-1, Iowa Black-FQ and Dabcyl \\
\hline
\end{tabular}

the $\mathrm{MB}$ is in its stem-loop structural conformation (hairpin) occurs by two mechanisms.

The first mechanism is called dynamic quenching and includes Föster's resonance energy transfer (FRET) and Dexter transfer, also named electron transfer quenching. In the dynamic quenching mechanism, the photon from the reporter is not released to the environment because a longrange dipole-dipole interaction occurs between reporter and quencher. For the dynamic quenching mechanism, the transfer efficiency of the energy depends on the spectral overlap between the emission spectrum of the reporter and the absorption spectrum of the quencher [54], the quantum yield of the donor, the relative orientation (also referred to as dipolar moment), and the distance between the two groups [55]. For a $50 \%$ of FRET efficiency, a distance in the range of 20-70 A (Föster's distance) is needed between the reporter and quencher, losing all the quenching efficiency at a distance $\geq 100 \AA$ ( $10 \mathrm{~nm})$.

The second mechanism called static quenching [56], requires the formation of ground-state complexes and the mechanism depends on the stem sequence, the linkers, and reporter-quencher pair used in the MB. The most important contributor in the quenching phenomenon is the static or contact quenching; the name describes the nature of the process, which occurs only when reporter and quencher are in close proximity, permitting the physical contact between them. Under these circumstances most of the energy transferred is not emitted as light, but emitted in the form of heat through a nonirradiative process [57]. This phenomenon occurs for all the nonfluorescent quenchers and determines basal fluorescence value in the absence of target and the signal-to-noise ratio of the $\mathrm{MB}$. The most frequently used nonfluorescent quenchers in $\mathrm{MB}$ synthesis are Dabcyl (4([4'-(dimethylamino)phenyl]azo)benzoic acid), Black-Hole quenchers BHQ1 and BHQ2, and Iowa Black FQ and RQ. Typical static quenching efficiency for these quenchers is in the range of $85-97 \%[54,57]$. These quenchers could be paired with various reporters (Table 1). Dabcyl is practically a universal quencher for near-infrared reporters although its absorption peak is around $475 \mathrm{~nm}$. Worth mentioning, this quencher is the least expensive of all.

Most recently, it has been reported that guanine bases can be utilized as quenchers in MB design (a method known as
G-quenched MB) $[59,60]$. Guanine bases work as quenchers when present at the opposite end of the reporter. The guanine bases could be placed as overhang or not. MBs without overhanged guanines show only a $15 \%$ increment in fluorescence intensity moving from the unbound state (in the absence of target) to the target-hybridized form [61], but when using two overhanged guanines a 2-fold is observed [62]. Guanine bases function as quenchers for a variety of reporters, including pyrene, coumarin, acridone, and 6FAM. Using guanine bases as quenchers improves the yield of $\mathrm{MB}$ obtained during the synthesis and reduces significantly its cost. G-quenched MBs have not been used for RNA imaging in live-cell assays, it is a field waiting to be explored. The structure and function of G-quenched $\mathrm{MB}$ and other quencher-free probes are widely discussed in reference [63].

3.2. Thermodynamics and Design. The MB-target hybridization is due to Watson-Crick basepairing. Experimental evidence (thermal denaturing assays) and binary models that simplify the real behavior of the phenomenon considering only the beginning of the hybridization kinetics and the end (steady-state), support the fact that for a given MB-perfectmatched target pair the melting temperature is $13 \pm 3^{\circ} \mathrm{C}$ higher than for the corresponding single-mismatched target $[26,27,57]$. The capability of a probe to discriminate perfect a perfect matched and single mismatched target is known as selectivity potential, and its magnitude is determined by the difference of the temperatures at the transition phases [64].

Linear probes have just two possible states, one free or unbound and the other bound to a target. Whereas MBs have three possible states, free with stem-loop conformation, free as a random coil and bound to its target (Figure 1(b)). In terms of free energy a $\mathrm{MB}$ is most stable in stem-loop conformation (hairpin) than in random coil state; therefore, such transitions most be brief. These suggest that when the temperature increases and the dissociation between the target and the MB occurs, the MB will acquire the stem loop conformation preferentially over the random coil state [6567]. The previously described phenomenon explains the high signal to background ratio observed with MBs. This suggest also that a more stable stem (due to higher C-G content or stem length) will produce a higher signal to background ratio. MBs with more stable stems would show enhanced 
selectivity because the $\mathrm{MB}$ will hybridize only when the interactions MB-targets are strong enough to overcome the stem stability. However, a word of caution, MBs with more stable stems may not hybridize to its target at a physiological temperature, preventing its use for cellular studies. Thus a delicate balance between hairpin stability (stem design) and MB-target selectivity must be reached for successful use of MBs in living cell assays.

3.3. Balance between Selectivity and Hybridization Rate. Clearly the greater advantage of $\mathrm{MB}$ over linear probes is its enhanced selectivity, which result from the hairpin stemloop structure attained by the MB in the nonhybridized state (not associated to its target). The stability of the hairpin conformation is ensured by building more stable stems (either increasing its C-G content or the stem length). Unfortunately, increasing stem strength decreases also the hybridization rate. For a given $\mathrm{MB}$ the rates of hybridization decrease between one and two orders of magnitude when the stem length is increased from two to four nucleotides [27]. Shorter stems produce less stable hairpin structures, and in consequence reduce the signal background ratio and the selectivity of the MB-target interaction. For an optimal stem design, it is necessary to determine the balance between selectivity and hybridization rate for a given assay [26, 27, 68]. A typical $\mathrm{MB}$ has a stem of 5-7 nucleotides and a loop of 15-25 nucleotides in length (Figures 2(a) and 2(b)) and hybridize its target using only the loop region (Figure 2(b)). In order to accelerate the hybridization rate for MBs with more stable stems, one can increase the loop length, therefore augmenting the region of the $\mathrm{MB}$ that hybridize to the target. Another possibility, which prevents increasing the length of the loop, but ensures faster hybridization rates, is to include the stem sequence as part of the complementary region that will hybridize to the target. The MB could hybridize the target using one arm of the stem totally (Figure 2(c) for the $3^{\prime}$ arm or Figure $2(\mathrm{~d})$ for the $5^{\prime} \mathrm{arm}$ ) or partially, or using partially both arms of the stem (Figure 2(e)). MBs using totally one arm of the stem to hybridize the target are known as shared stem (Figures 2(c) or 2(d)) [57]. For a given target sequence one shared-stem $\mathrm{MB}$ offers a high hybridization rate in comparison with a $\mathrm{MB}$ with equal number of complementary nucleotides, using only the loop as hybridization region, this is due to the complementary-nucleotides/MB-length ratio

$$
\text { Hybridization rate } \propto \frac{\text { complementary nucleotides }}{\text { MB-length }} .
$$

For living cells assays the MB have to discriminate among perfect matched and single mismatched targets at $37^{\circ} \mathrm{C}$, it means that the melting temperature of the MB-single-mismatched target pair have to be less than $37^{\circ} \mathrm{C}$, while the melting temperature of the $\mathrm{MB}$-perfect-matched target pair must be above $37^{\circ} \mathrm{C}$ [69]. This requirement could be covered during the design of the stem stability, loop length, and/or regions that will participate in the hybridization. If the $\mathrm{MB}$ is designed with too high MB-target melting temperatures, it will be impossible to differentiate between the perfect complementary and the single mismatch targets. On the other

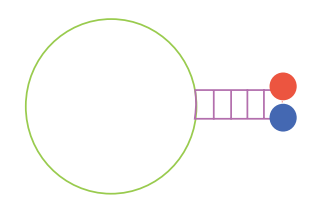

(a)



(b)

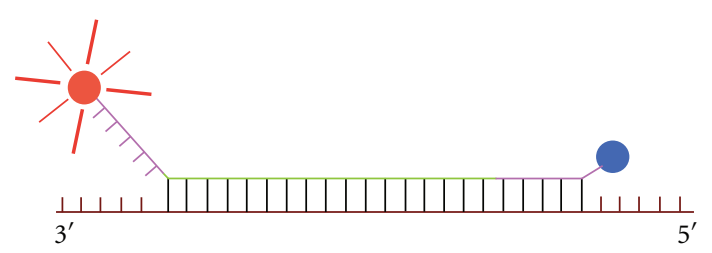

(c)

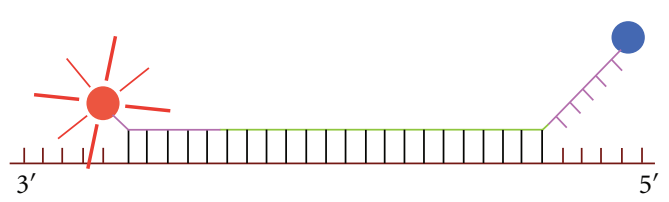

(d)



(e)

Figure 2: Different positions for MB-target hybridization. The loop region is illustrated in green and the stem in purple for all panels, target is brown and the bonds MB target are black ((b), (c), (d) y (e)). (a) MB with a stem of five nucleotides in the stem-loop hairpin conformation. (b) MB with a stem of five nucleotides and twenty two nucleotides in the loop, target hybridization occurs only at loop region. (c) MB with a stem of five nucleotides and a stem of seventeen nucleotides, using the loop and all the $3^{\prime}$ arm to hybridize the target ( $3^{\prime}$ shared stem MB). (d) MB with a stem of five nucleotides and a loop of seventeen nucleotides, using the loop and completely the $5^{\prime}$ arm to hybridize its target ( $5^{\prime}$ shared stem MB). (e) MB with a stem of five nucleotides and loop of eighteen nucleotides using partially both arms to hybridize its target (two nucleotides of every arm). Notice that a target that makes possible the design of a $\mathrm{MB}$ that hybridizes it using completely both arms could have a strong secondary structure that makes impossible the MB-target hybridization. 
hand, if the MB-target melting temperatures were reduced too much, just a little fraction of the perfectly complementary target would be bound to the MB at physiological temperatures.

\section{Chemistry Approaches for High Performance Molecular Beacons}

When a MB will be used for RNA imaging in living cells, it must have minimal requirements in terms of sensitivity and selectivity, to prevent false-positive signals derived from nonspecific interactions, like protein binding and/or nuclease digestion. One could imagine that if the MB were digested by a nuclease, then the separation of the quencher and the reporter would necessarily result in fluorescence signal, which would not reflect MB-target interactions. Similarly, if protein binding diminishes quencher efficiency, fluorescence increments will not reflect the expected MB-target association.

4.1. MB with Chemically Enhanced Sensitivity. Some RNA species have a very low number of copies in living cells (e.g., microRNAs), which represent a big challenge for detection using MB. In such case, it is necessary to build MB with enhanced sensitivity and increased signal to background ratio. Increasing the efficiency of the quenching or increasing the fluorescence intensity emitted by the reporter after target hybridization could accomplish this. Most of the recent strategies are focused on increasing the fluorescence intensity of the reporter.

A typical quenching efficiency by contact or static quenching is in the range of $85-97 \%$ [70], depending on the factors previously discussed. Increasing the quenching efficiency would necessarily result in increased signal to background ratios. The increment in the dynamic range increases the difference of the fluorescence emitted by a population of MB-perfect-matched target hybrids in comparison with an equivalent population of MB-single-mismatched targets.

Recently developed MB synthesis strategies to increase the quenching efficiency consist in adding several quencher molecules in tandem (the so-called superquenching). Recent MBs have been synthesized using a FAM reporter and two or three Dabcyl molecules as quenchers (Figure 3) at the $5^{\prime}$ end [19]. This strategy results in an increment in quenching efficiency from $92.9 \%$ for one Dabcyl to $98.75 \%$ for two Dabcyl and $99.7 \%$ for three Dabcyl quenchers. Also the signal enhancement increases from 14 (one Dabcyl) to 80 (two Dabcyl) and 320 units (three Dabcyl molecules), increasing significantly the chances of detecting very low quantities of target [19]. Another interesting observation resulting from the use of three Dabcyl in tandem is that the increase in the hydrophobic interactions that occurs between the reporter and quenchers cause that the melting temperature of the $\mathrm{MB}$ stem increases in $4^{\circ} \mathrm{C}$ in comparison with stems having a single Dabcyl quencher. In theory, the higher melting temperature could enhance the capability of the MB to discriminate between perfect matched and single mismatched targets.

Since fluorescence quenching is based on static and dynamic quenching mechanisms and the efficiency of both depends on molecular distances and spatial orientation (dipole moment), having multiple quenchers in tandem may facilitate that one or more of them attain the correct spatial position in respect to the reporter, thus explaining the high efficiency of the super-quenching phenomenon.

Some polymeric fluorescent dyes could be employed to increase the fluorescence intensity and also the sensitivity of MB. Poly(phenylene ethynylene) (PPE) [71] is a water soluble polyelectrolyte with a high quantum yield [72]. Using a novel polymerization reaction it is possible to couple PPE directly to oligonucleotides. PPE have the highest fluorescent intensity compared to common fluorescent dyes used in $\mathrm{MB}$ synthesis. PPE has a fluorescent intensity around 20-fold higher than $\mathrm{Cy} 3$ and more than 6-fold in comparison with Alexa Fluor 488 (the fluorescent dye with highest fluorescence intensity currently used for MB building). In addition the fluorescence intensity of a single PPE chain is about $75 \%$ of the brightness intensity obtained with a quantum dot. The Dabcyl quencher shows good quenching performance with PPE. Nevertheless, super-quenching with Dabcyl could increase the performance of a PPE-based MB and enhance the signal to a level that may facilitate the identification of low abundance RNA molecules in living cells.

4.2. Nuclease Resistant MB. Cells use nucleases for nucleic acid catabolism and reuse the nucleotides for nucleic acid synthesis. Nucleases are used for cellular defense against foreign nucleic acids and for degradation of damaged DNA. Unfortunately for the researcher, nucleases also depredate MB [73, 74], which constitutes a problem for RNA imaging in living cells using these probes. Recent experiments show that living cells exhibit increments in fluorescence intensity after 45 minutes of MB delivery, even in the absence of a target [75]. Data indicate that this fluorescence increment is due to $\mathrm{MB}$ nuclease-mediated degradation. To produce nuclease resistant $\mathrm{MB}$ with improved stability at the cytoplasm, modified nucleotides have been incorporated in MB synthesis. These modified nucleotides include 2'-O-methylated [76$78]$, phosphorothioate derivatives $[79,80]$, peptide nucleic acids (PNA) [81, 82], and locked nucleic acids (LNA) [83]. 2'-O-methylated MBs offer good nuclease resistance and also resist RNase activity [76]; the main disadvantage for its use is the high background due to nonspecific interactions with proteins [84-86], another common problem is probe accumulation at the nucleus [87] and mitochondria [88]. In order to avoid the nuclear accumulation a quantum dot (QD) has been recently linked to the $2^{\prime}$-O-methylated MB [89], the linker is a biotin-dT group at the $3^{\prime}$ stem. The slow accumulation of the $2^{\prime}$-O-methylated $\mathrm{MB}$ at the mitochondria is reported only when using cyanine labeled MBs. PNA-based MBs have good affinity for both DNA and RNA targets in conjunction with high resistance to nuclease degradation. However, their reduced solubility and occasional aggregation limits its use for in vivo localization studies. LNA have a bicyclic furanose unit locked in an RNA-mimicking sugar conformation. LNA-based MBs show higher affinity for its target than DNA-based MBs; also the hybridization rate is slower in comparison. The use of chimeric DNA-LNA MBs results in nuclease resistant probes, 


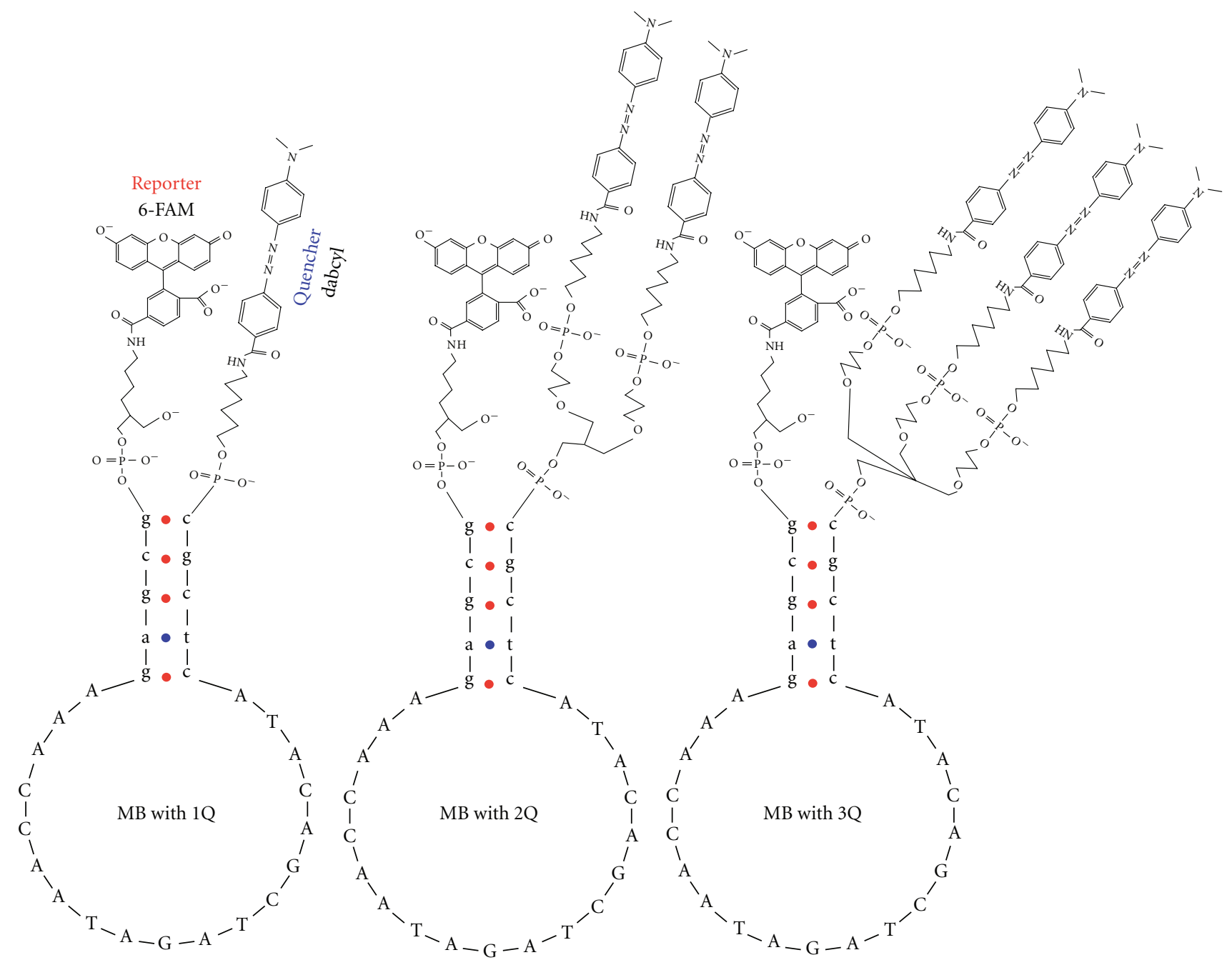

FIGURE 3: Structures of the superquenched MB. MB with one (1Q), two (2Q), and three (3Q) Dabcyl quenchers. The structures are represented in their oxidized state. The linker structures, the reporter linked to the $3^{\prime}$ end and the quencher or quenchers attached at the $5^{\prime}$ terminus correspond to [19].

with very high selectivity. It is important to take in consideration the LNA/DNA ratio of the chimeric probes, and if LNA bases will be part of the stem or not. By lowering the DNA/LNA ratio the hybridization rate is increased but also the nuclease degradation [83]. If the LNA bases are located at the stem, MB stability increases significantly, improving the selectivity. A shared-stem design with a four basepair stem and alternating DNA/LNA bases (ratio 1:1) has been recently suggested for living cell applications [90]. With this design a reasonable hybridization rate is obtained in addition to lower unspecific protein interactions and high nuclease resistance.

A novel strategy to avoid the possibility of the stem interactions with other nucleic acids or MB-MB between sticky ends consists in the use of L-DNA (specular isomer for the D-DNA) in the stem region [91]. D-DNA cannot interact with L-DNA and form left handed double helix. This design increases stem stability and MB selectivity.

\section{Methods for MB Delivery into Cells}

The efficient delivery of the MB into living cells is not an easy task. The method used must be efficient in terms that sufficient probe must be introduced in order to detect even low abundance RNA. Many delivery methods have been explored for MB introduction including microinjection, reversible cell membrane permeabilization, electroporation, MB linked to cell-penetrating peptides, and bioballistics. Needless to say that there is not a single method that can be used in all experimental conditions, therefore method selection is also based on the sample utilized.

Many transfection agents produce punctuate fluorescent patterns due to the passage of the MB by the endocytic pathway. Experimental evidence shows that linear fluorescently labeled probes enter in the endosomal/lysosomal pathway with the concomitant nuclease-mediated degradation. Reduced amounts of the probe may escape from the endocytic 
pathway $(0.01-10 \%)$ after several hours. For these reasons a delivery method in which the MB could enter the cell cytoplasm evading the endosomal pathway is highly desirable (e.g., microinjection, permeabilization of cell membranes by toxins, MB linked to cell penetration peptides, electroporation, or bioballistics).

5.1. Microinjection. The microinjection $[42,92]$ is in fact the most invasive method for MB delivery into living cells, which may result in cell damage and/or cell death. In the case where cells do not die, the injection could interfere with normal cellular functions and also produce altered or not reproducible results. An other disadvantage is the low number of cells that could be injected, given the fact that one must inject cell by cell. The major advantage is that low MB volumes are used reducing the cost of $\mathrm{MB}$ delivery. When using this method it is important to include a nonfluorescent dye (ink) in the solution, to ensure that the small volume enters the cell. Ink selection is also relevant to reduce side effects. Perhaps the main constrain for using this method is that a specialized injection system must be used in order to deliver a few nanoliters (nL) into the cell. Typically mammalian cells cannot be injected with volumes larger than $5 \mathrm{~nL}$ without compromising cell viability.

5.2. Toxin-Mediated Cell Membrane Permeabilization. A nonendocytic delivery method is the reversible membrane permeabilization mediated by toxins. Streptolysin O (SLO) is a bacterial toxin produced by streptococci hemolytic strain (Streptococcus pyogenes) having the ability to form pores on the cell membrane [93-95]. SLO binds as a monomer to cholesterol located on the cell plasma membrane, later SLO oligomerizes into a ring structure, producing a transient pore with a diameter in the range of $25-30 \mathrm{~nm}$. The pore allows the entrance of macromolecules like the MB. The SLO cell membrane permeabilization method must be conducted in serum-free conditions; after membrane permeabilization the addition of the culture media containing serum inactivates the toxin $[93,96]$. Since cholesterol composition is not a constant among cell types, the permeabilization process have to be optimized for every cell type, testing the MB entrance efficiency under different conditions of temperature, SLO concentration, cell number, and incubation time. We have found the use of combined MB-target solutions extremely useful for such testing to visualize the increment of cytosolic fluorescence as the MB-target enter the cell via the SLO pore.

5.3. MB Linked to Cell-Penetrating Peptides. There are several naturally occurring peptides with the capacity to penetrate cellular membranes (CPP: cell-penetrating peptides) [9799]. One of the most widely used is, for instance, the transactivating transcriptional activator (Tat) from human immunodeficiency virus (HIV-1). Another peptide is a fragment of the Drosophila antennapedia homeodomain (RQIKIWFQNRRMKWKK) and the peptide VP22 from the tegument of the herpes simplex virus type 1 (HSV-1). In general, CPPs are short peptides rich in basic amino acids presenting an amphipathic arrange. CPPs penetrate across the cellular membranes without toxic effects and with very high efficiency (near to $100 \%$ of cells exposed are affected). The mechanism underlying CPP internalization prevents membrane destabilization, loss of cellular integrity and appears to be independent from the endocytic pathway (therefore reducing $\mathrm{MB}$ degradation by nuclease attack). Currently the most widely used CPP is the HIV-1 Tat peptide, and also the best studied due to its small size and high delivery efficiency.

CPPs deliver a wide variety of cargo molecules in culture cells or tissues $[100,101]$. A major advantage of CPPs is that they do not interfere with specificity or sensitivity of MBs.

Recently CCP and NLS peptides (peptides with nuclear localization sequences) were conjugated to MB by different linkers (being the most common the carbon saturated chains (Figures 5(b), 5(b') and 5(c)). The maleimide-thiol system is a very useful tool to conjugate $\mathrm{MB}$ with peptides. Maleimide reacts with moieties having thiol groups (Figure 4(a)), like cysteine or free thiol groups. The first option is to have a sulfhydryl in the terminus of the MB linker to react with maleimide at the terminus of the peptide (Figure 4(b)). The second option is the opposite, in that the MB linker has the maleimide and the peptide has the thiol group (Figure $4\left(b^{\prime}\right)$ ). A third option consists in having two sulfhydryl groups, one at the terminus of the MB linker and another at the terminus of the peptide (Figure 4(c)) forming a disulphide bond. This last option is the most versatile, because it facilitates the separation of the $\mathrm{MB}$ and the peptide using a reducing environment. Using CCPs as tools made possible imaging mRNAs like GAPDH recently [102]. Another interesting strategy involves the linking of the MB to peptides with nuclear localization signals (NLSs), in conjunction with SLO facilitates reaching nuclear targets like U1, U2, or U3 [103] (Figure $4(\mathrm{~d})$ ).

5.4. Electroporation. Electroporation methods have been used for delivering MBs into the cytoplasm of living cells, because electroporation avoid the endosomal pathway and in consequence reduces $\mathrm{MB}$ degradation. In the past, electroporation was associated with low cellular viability, but recent advances in this technology have led to a reduction in the events associated with cell damage or stress, including heat generation, metal ion dissolution, $\mathrm{pH}$ variations, or free radicals generation. Recently a novel electroporation method called microporation shows that a short time after the electroporation process occurs, a uniform distribution of the probe is observed at the cytoplasm [104]. Using this novel method high delivery efficiencies superior to $90 \%$ and cell viability near to $86 \%$ are observed [104]. With microporation (or any electroporation method) cells must be in suspension during the delivery procedure, therefore a time is required for cell to adhere before imaging studies can be conducted. This waiting period prevents the observation of early events of RNA mobilization or transport, a limitation to be taken into account during experiment planning.

5.5. Bioballistics. In the bioballistics technique, heavy metal particles are coated with molecules (e.g., MB) and propelled into the cells via a gas gun. The first application of this 


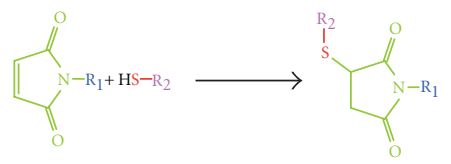

(a)



(b)

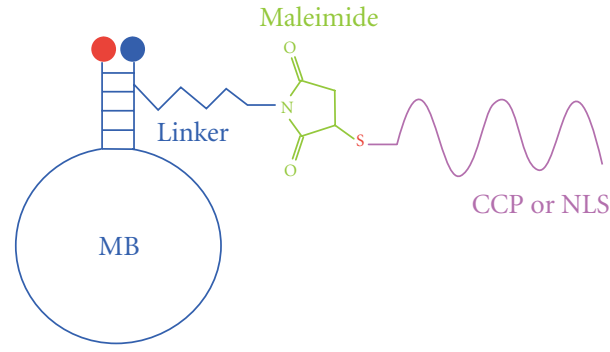

$\left(\mathrm{b}^{\prime}\right)$

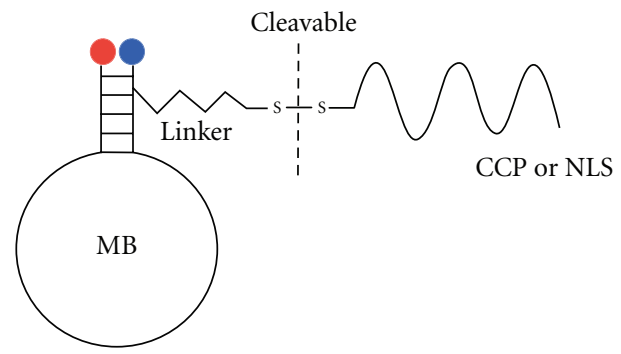

(c)

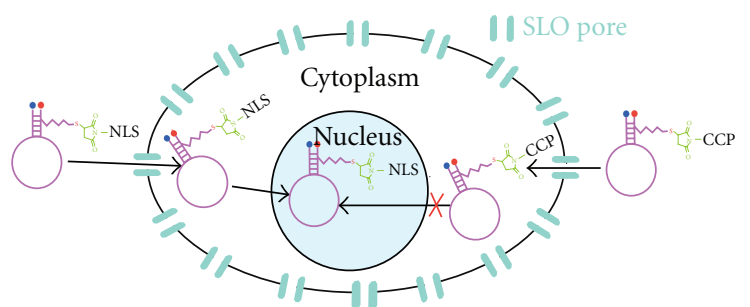

(d)

FIGURE 4: MB linked to penetrating peptides. (a) Reaction of conjugation among the maleimide molecule with a carrier group $\left(\mathrm{R}_{1}\right)$ and the thiol group of another molecule. This reaction may possibly link MB-peptide and occurs at a pH between 6.5-7.5. (b) One possibility using the maleimide-thiol system is that the peptide (NLS or CCP) it is linked to the maleimide across the secondary amine and reacts with a sulfhydryl group at the terminus of the MB hydrocarbon linker. ( $\left.b^{\prime}\right)$ The other possibility for the maleimide-thiol system is that the maleimide is linked at the terminus of the MB hydrocarbon linker and reacts with a thiol group at the peptide (NLS or CCP). (c) The link between the hydrocarbon linker of the MB and the peptide also could be across a disulphide bridge, in this case exists the possibility to cleave the bond in a reducing environment. (d) Using SLO to make permeable the cytoplasmic membrane is possible to introduce a MB linked to an NLS peptide to the cytoplasm with the objective that it be transported into the nucleus by the cellular machinery. For a CCP-linked MB the entrance to the nucleus is impossible. 


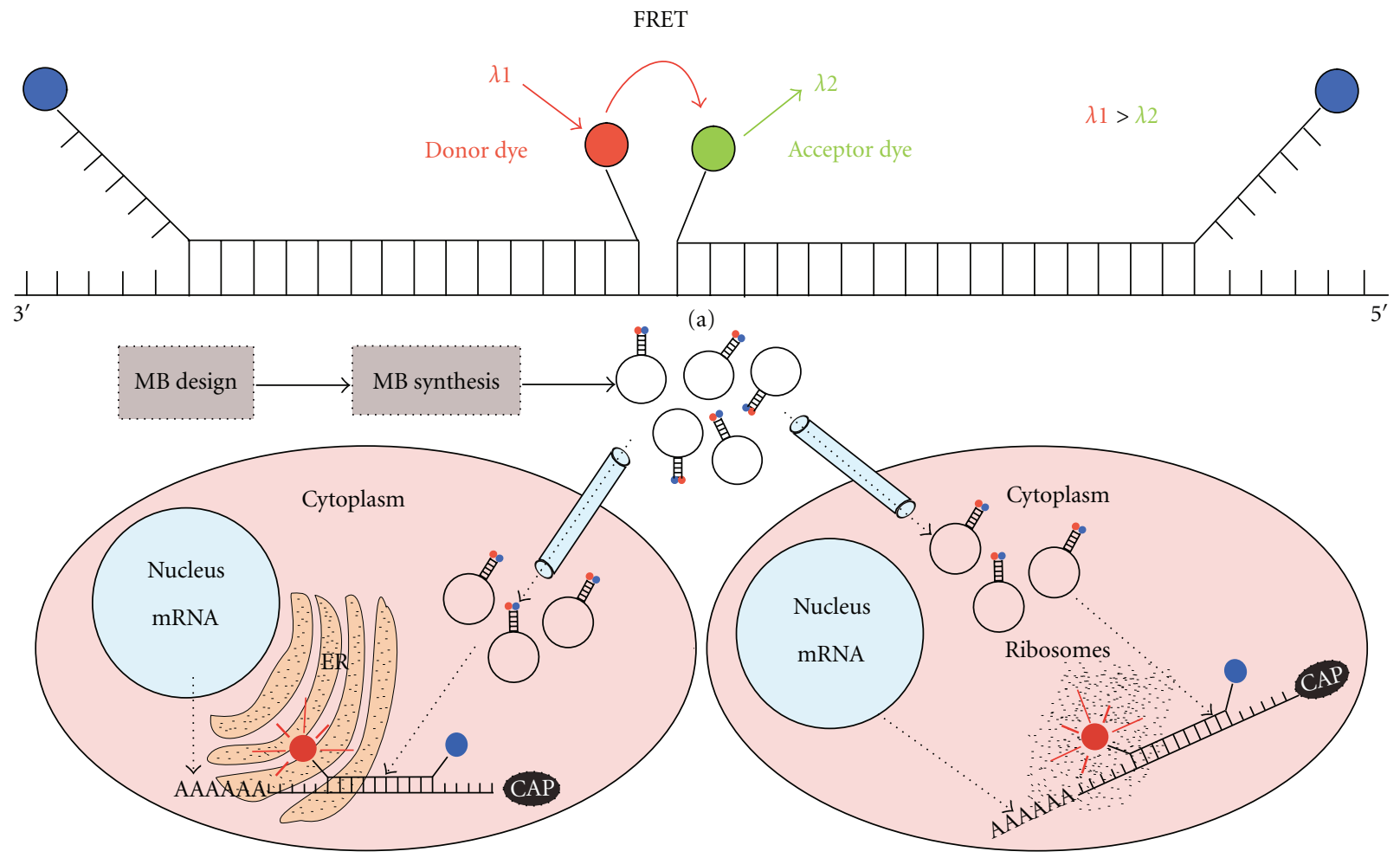

(b)

(c)

FIgURE 5: Approaches for RNA visualization in living cells. (a) In order to reduce the possibility of false-positive signals and also increase the specificity, one can design two shared stem MB having a pair reporters compatible with FRET, one to serve like a donor dye (red circle) and the other like a acceptor dye (green circle). With this strategy the sequence to be recognized increases its length and thus the specificity of the assay (observe that one MB needs to have the reporter at the $3^{\prime}$ end and the quencher at the $5^{\prime}$ end, in a not conventional attachment). After the MB design and synthesis the probe could be delivered using microinjection; in conjunction with other MB or fluorescent dyes could be used to measure RNA distribution at subcellular level. For example it is possible to use a specific fluorescent dye for the endoplasmic reticulum (ER) and also a MB designed to hybridize a given sequence of the ribosome. If a particular mRNA (based on the fluorescence of the $\mathrm{MB}$ ) colocalizes with the ER dye and ribosome dye it means that this mRNA is translated in ribosomes at ER (b) or if the mRNA signal colocalizes only with the ribosome dye means that the mRNA translation occurs at free ribosomes (c); also it is possible that the mRNA translation takes place at both free and ER associated ribosomes. These are only some examples of the power of using MB in combination with other compartment or structure-specific dyes.

technique was in 1987 on plant cells [105]. In 1990 the technique was used for the first time for nucleic acids delivery into mammalian cells [106]. The biobullets usually are made with biocompatible metals, for example, gold or tungsten, having diameters from 1 to 5 micrometers [107]. Bullets must be coated with nucleic acids of interest prior to loading into the gun. The particles are propelled by the discharge of a gas into the gun chamber at very high pressure, usually helium [108] or water vapor [106]. The particles enter into the cytoplasm independently of the endosomal pathway, thus avoiding degradation [109]. A disadvantage of this method is that the cell membrane could present alterations that may induce cell stress. Bio-ballistic techniques are less invasive than microinjection and membrane alterations associated with the shot are usually short lasting. Perhaps the major disadvantage for bioballistics is that there is no control over the amount of $\mathrm{MB}$ delivery into the cell. Also the amount of MB entering each cell is variable. This method is most suited for cell population studies, but may hamper the interpretation of single cell imaging studies.

\section{Real-Time Monitoring of RNA in Living Cells Using MB}

6.1. mRNA Imaging in Living Cells Using MB. MBs have been only recently used for monitoring mRNA in living cells. MBs are particularly suited for mRNA studies because these RNA molecules are usually in high abundance, or at least higher than noncoding RNAs, for instance. For a successful MB design one needs to take into consideration all the factors involved in mRNA recognition by MB. Perhaps the most complicated issue is the selection of an appropriate target region in the mRNA sequence. One must first analyze the predicted secondary and tertiary structures in the mRNA target in an attempt to identify those regions showing minimum structure $[68,110]$. In general, heavy secondary structure hampers MB binding to the target at room temperature, or results in very slow association kinetics. One should always consider that the determination of the target secondary structure is based on in silico predictions, which may or may not reflect the real structure of that region selected in vivo. 
Another relevant consideration is to ensure that the region selected is not present in other nucleic acid in the cell. This can be partially accomplished using alignment tools like Blast [111], using the MB sequence as input. To ensure that the MB hybridizes with the expected target, a clever strategy has been recently implemented. In this strategy, the use of two shared stem MBs (one $3^{\prime}$ shared stem and the other $5^{\prime}$ shared stem) in adjacent positions is required (Figure 5(a)), both MBs are designed as FRET pair reporters to eliminate the possibility that false positives detection occurs $[112,113]$. Shared stem design reduces the degree of freedom in the movements of both components of the FRET pair, enhancing FRET efficiency. Using two MBs reduces significantly the possibility of false positives, since having adjacent sequences in a given RNA that is recognized by two independent MBs is equivalent to recognizing a larger sequence (the sum of the MB-target complementary nucleotides in every MB).

Another promising application for MB research involves its use in conjunction with fluorescent dyes for specific organelles or subcellular structures. For example an assay designed to identify if a given mRNA is translated at ribosomes associated with endoplasmic reticulum (ER) or in free ribosomes could be developed, using a selective fluorescent dye for the ER and a MB designed to hybridize with the ribosomes and a second MB designed to detect the mRNA. With these elements it is possible to observe the colocalization of the mRNA within the ER and ribosomes simultaneously (Figure 5(b)) or visualize the colocalization of the mRNA with ribosomes only (no ER labeling) if the translation occurs at free ribosomes (Figure 5(c)).

6.2. Monitoring Gene Expression in Living Cells. The first assays where $\mathrm{MB}$ were involved focused only in detecting synthetic targets in in vitro studies, but in 2003 Bratu et al. demonstrated that a MB constitutes a powerful tool for RNA imaging and could be used for visualizing the distribution and transport of mRNA in living cells [48]. To reduce the background noise and ensure that the MB hybridizes its target, two MBs that recognize adjacent positions at the target were designed. The binding of both MBs resulted in FRET signal (energy transfer from one $\mathrm{MB}$ to the adjacent $\mathrm{MB}$ ), indicating that both MBs were bound to adjacent regions in the target $[112,113]$. The robustness of this method allows not only the identification of the mRNA target localization in the cell, but also opens the possibility to follow the transport of the mRNA through the cell in real time. Diffusion coefficients of the mRNA can be accurately measured combining fluorescence recovery after photobleaching (FRAP). In addition Santangelo et al. were beyond and analyzed the distribution and transport of the mRNA with respect in organelles from human fibroblasts. For this study MBs were used in combination with fluorescent stains of mitochondria, using spectral resolution Santangelo et al. demonstrated that both mRNA for glyceraldehydes 3-phospahate dehydrogenase and K-ras were specially enriched within the mitochondria [112]. Recently Wang et al. described a method to determine the expression levels of a specific RNA using MBs [114]. They use a system with two MBs and a reference probe as an internal standard for ratiometric analysis. The reference probe was used to avoid the variations due to different $\mathrm{MB}$ concentrations in the cell. One MB was used to detect the desired mRNA whereas the other MB was used to hybridize a house keeping mRNA, serving as reference. Three different cell types were used to compare expression levels of the mRNA of interest with excellent results.

Even though several methods for the study of unique mRNA molecules have been implemented, monitoring multiple RNA molecules in the same cell remains a technical challenge. The ratiometric analysis offers a good approach for the quantification of gene expression [115], enabling a more accurate estimation of mRNA levels. Even though in this particular study two different MBs were used, one can envision an extension of this method to study several RNA molecules simultaneously using spectrally different fluorescent reporters for each $\mathrm{MB}$.

6.3. Monitoring Viral Genomic RNA Replication in Living Cells. RNA viruses have a genome composed by RNA with structural differences, which allow their classification into groups. Three groups of RNA viruses have been described, group III with a segmented double-stranded RNA genome, group IV with positive-sense single-stranded RNA genome, and group $\mathrm{V}$ with a negative-sense single-stranded genome. Methods for live-cell imaging of viral genomic RNA replication using MBs are currently available. Recently a method was implemented to monitor virus replication in living cells with the B6 coxsackievirus [116]. Virus replication was monitored using 2'-O-methylated RNA-MB. MB was introduced in the cells using a thiol-maleimide bridge linked to the Tat peptide. The MB was directed to a sequence of 18 basepairs located in the $5^{\prime}$ noncoding region of the viral genome. Coxsackieviruses belong to a Picornaviridae family having a positive-sense single-stranded genome. In a different report, researchers monitored genomic RNA replication of the bovine respiratory syncytial virus (bRSV) [46] using a MB directed to tandem-repeated consensus-sequences at intergenic regions, in order to amplify the signal. Detection of viral genomic RNA in living cells is a promising application because it facilitates the detection of viruses without the need for RNA purification, cDNA synthesis steps and/or amplification procedures, and also open the possibility of obtaining spatial-temporal information contributing to the understanding of viral replication, delivery, or propagation mechanisms. These contributions could facilitate the development of drugs for viral infection treatment or rapid diagnostics techniques. Undoubtedly, MBs will impulse viral research by facilitating the study of genome replication and transport in living cells, something difficult to envision before the MB era.

\section{Conclusion}

We have discussed in this paper important advances in the design, synthesis, and use of MBs since its introduction by Tyagi and Kramer in 1996. We have highlighted relevant issues involved in sequence selection, loop, and stem considerations needed for a successful MB design. We 
have mentioned also new developments in MB synthesis using modified nucleic acids highlighting its advantages and limitations. Finally, we have gathered recent studies where MBs have been used in rather clever experiments directed to the study of RNA localization and dynamics in living cells.

The development of novel fluorescent indicators with greater dynamic range in combination with robust quenchers, in the next generation of MBs, will provide exceptional tools for RNA studies in living cells and tissues. The combination of such tools with powerful imaging techniques, such as FRAP, FLIM, TIRFM, and multiphoton confocal microscopy promises the possibility to conduct such studies in living organisms.

Finally, a poorly explored area in $\mathrm{MB}$ research is the use of these tools in diagnostics. One can easily envision methodologies capable of identifying replicating viruses in human samples, using $\mathrm{MB}$ in combination with fluorescent assays without the need of time consuming more elaborated techniques such as qPCR.

\section{Acknowledgments}

This work was partially supported by a grant from the Instituto de Ciencia y Tecnología del Distrito Federal (ICYTDF) and Dirección General de Asuntos del Personal Académico (DGAPA) to L. Vaca. R. Monroy-Contreras is a fellow from the Consejo Nacional de Ciencia y Tecnologia (CONACyT). The technical assistance from Alicia Sampieri is greatly appreciated.

\section{References}

[1] V. Glišin, R. Crkvenjakov, and C. Byus, "Ribonucleic acid isolated by cesium chloride centrifugation," Biochemistry, vol. 13, no. 12, pp. 2633-2637, 1974.

[2] C. Auffray and F. Rougeon, "Purification of mouse immunoglobulin heavy-chain messenger RNAs from total myeloma tumor RNA," European Journal of Biochemistry, vol. 107, no. 2, pp. 303-314, 1980.

[3] P. Chomczynski and N. Sacchi, "Single-step method of RNA isolation by acid guanidinium thiocyanate-phenol-chloroform extraction," Analytical Biochemistry, vol. 162, no. 1, pp. 156-159, 1987.

[4] R. K. Saiki, S. Scharf, and F. Faloona, "Enzymatic amplification of $\beta$-globin genomic sequences and restriction site analysis for diagnosis of sickle cell anemia," Science, vol. 230, no. 4732, pp. 1350-1354, 1985.

[5] J. C. Alwine, D. J. Kemp, B. A. Parker et al., "Detection of specific RNAs or specific fragments of DNA by fractionation in gels and transfer to diazobenzyloxymethyl paper," Methods in Enzymology, vol. 68, pp. 220-242, 1979.

[6] V. E. Velculescu, L. Zhang, B. Vogelstein, and K. W. Kinzler, "Serial analysis of gene expression," Science, vol. 270, no. 5235, pp. 484-487, 1995.

[7] L. Diatchenko, Y. F. C. Lau, A. P. Campbell et al., "Suppression subtractive hybridization: a method for generating differentially regulated or tissue-specific cDNA probes and libraries," Proceedings of the National Academy of Sciences of the United States of America, vol. 93, no. 12, pp. 6025-6030, 1996.
[8] P. Liang and A. B. Pardee, "Differential display of eukaryotic messenger RNA by means of the polymerase chain reaction," Science, vol. 257, no. 5072, pp. 967-971, 1992.

[9] N. Lisitsyn and M. Wigler, "Cloning the differences between two complex genomes," Science, vol. 259, no. 5097, pp. 946951, 1993.

[10] M. D. Adams, M. Dubnick, A. R. Kerlavage et al., "Sequence identification of 2,375 human brain genes," Nature, vol. 355, no. 6361, pp. 632-634, 1992.

[11] M. Schena, D. Shalon, R. W. Davis, and P. O. Brown, "Quantitative monitoring of gene expression patterns with a complementary DNA microarray," Science, vol. 270, no. 5235, pp. 467-470, 1995.

[12] G. J. Bassell, C. M. Powers, K. L. Taneja, and R. H. Singer, "Single mRNAs visualized by ultrastructural in situ hybridization are principally localized at actin filament intersections in fibroblasts," Journal of Cell Biology, vol. 126, no. 4, pp. 863876, 1994.

[13] M. C. Vaccaro, S. Gigliotti, F. Graziani et al., "A transient asymmetric distribution of XNOA 36 mRNA and the associated spectrin network bisects Xenopus laevis stage I oocytes along the future A/V axis," European Journal of Cell Biology, vol. 89, no. 7, pp. 525-536, 2010.

[14] Y. Shinmyo, T. Mito, T. Matsushita et al., "Caudal is required for gnathal and thoracic patterning and for posterior elongation in the intermediate-germband cricket Gryllus bimaculatus," Mechanisms of Development, vol. 122, no. 2, pp. 231239, 2005.

[15] R. Krause, M. Hemberger, M. Messerschmid et al., "Molecular cloning and characterization of murine Mpgc60, a gene predominantly expressed in the intestinal tract," Differentiation, vol. 63, no. 5, pp. 285-294, 1998.

[16] M. Mione, Z. Lele, C. T. Kwong, M. L. Concha, and J. D. Clarke, "Expression of pcp4a in subpopulations of CNS neurons in zebrafish," Journal of Comparative Neurology, vol. 495, no. 6, pp. 769-787, 2006.

[17] S. Behrens, B. M. Fuchs, F. Mueller, and R. Amann, "Is the in situ accessibility of the 16S rRNA of Escherichia coli for Cy3-labeled oligonucleotide probes predicted by a threedimensional structure model of the 30 S ribosomal subunit?" Applied and Environmental Microbiology, vol. 69, no. 8, pp. 4935-4941, 2003.

[18] G. Bao, J. R. Won, and A. Tsourkas, "Fluorescent probes for live-cell RNA detection," Annual Review of Biomedical Engineering, vol. 11, pp. 25-47, 2009.

[19] C. J. Yang, H. Lin, and W. Tan, "Molecular assembly of superquenchers in signaling molecular interactions," Journal of the American Chemical Society, vol. 127, no. 37, pp. 1277212773, 2005.

[20] S. Tyagi and F. R. Kramer, "Molecular beacons: probes that fluoresce upon hybridization," Nature Biotechnology, vol. 14, no. 3, pp. 303-308, 1996.

[21] S. D. Bélanger, M. Boissinot, C. Ménard, F. J. Picard, and M. G. Bergeron, "Rapid detection of Shiga toxin-producing bacteria in feces by multiplex PCR with molecular beacons on the Smart Cycler," Journal of Clinical Microbiology, vol. 40, no. 4, pp. 1436-1440, 2002.

[22] S. D. Bélanger, M. Boissinot, N. Clairoux, F. J. Picard, and M. G. Bergeron, "Rapid detection of Clostridium difficile in feces by real-time PCR," Journal of Clinical Microbiology, vol. 41, no. 2, pp. 730-734, 2003.

[23] A. Beloukas, D. Paraskevis, M. Psichogiou, and A. Hatzakis, "The role of HIV-1 DNA as an additional marker of HIV-1 
infection," Current HIV Research, vol. 7, no. 3, pp. 255-265, 2009.

[24] M. G. Bergeron and D. Ke, "New DNA-based PCR approaches for rapid real-time detection and prevention of group B streptococcal infections in newborns and pregnant women," Expert Reviews in Molecular Medicine, vol. 3, no. 27, pp. 1-14, 2001.

[25] W. Chen, G. Martinez, and A. Mulchandani, "Molecular beacons: a real-time polymerase chain reaction assay for detecting Salmonella," Analytical Biochemistry, vol. 280, no. 1, pp. 166-172, 2000.

[26] G. Bonnet, S. Tyagi, A. Libchaber, and F. R. Kramer, "Thermodynamic basis of the enhanced specificity of structured DNA probes," Proceedings of the National Academy of Sciences of the United States of America, vol. 96, no. 11, pp. 6171-6176, 1999.

[27] A. Tsourkas, M. A. Behlke, S. D. Rose, and G. Bao, "Hybridization kinetics and thermodynamics of molecular beacons," Nucleic Acids Research, vol. 31, no. 4, pp. 1319-1330, 2003.

[28] I. Tapp, L. Malmberg, E. Rennel, M. Wik, and A. C. Syvanen, "Homogeneous scoring of single-nucleotide polymorphisms: comparison of the 5'-nuclease TaqMan $\AA$ assay and molecular beacon probes (BioTechniques (2000) 28 (732-738))," BioTechniques, vol. 28, no. 4, pp. 732-738, 2000.

[29] M. M. Mhlanga and L. Malmberg, "Using molecular beacons to detect single-nucleotide polymorphisms with real-time PCR," Methods, vol. 25, no. 4, pp. 463-471, 2001.

[30] S. A. Marras, F. R. Kramer, and S. Tyagi, "Genotyping SNPs with molecular beacons," Methods in Molecular Biology, vol. 212, pp. 111-128, 2003.

[31] L. B. Barreiro, R. Henriques, and M. M. Mhlanga, "Highthroughput SNP genotyping: combining tag SNPs and molecular beacons," Methods in Molecular Biology, vol. 578, pp. 255-276, 2009.

[32] L. G. Kostrikis, S. Tyagi, M. M. Mhlanga, D. D. Ho, and F. R. Kramer, "Spectral genotyping of human alleles," Science, vol. 279, no. 5354, pp. 1228-1229, 1998.

[33] L. G. Kostrikis, S. Shin, and D. D. Ho, "Genotyping HIV-1 and HCV strains by a combinatorial DNA melting assay (COMA)," Molecular Medicine, vol. 4, no. 7, pp. 443-453, 1998.

[34] G. Orrù, G. Faa, S. Pillai et al., "Rapid PCR real-time genotyping of M-Malton $\alpha 1$-antitrypsin deficiency alleles by molecular beacons," Diagnostic Molecular Pathology, vol. 14, no. 4, pp. 237-242, 2005.

[35] G. Orru, F. Coghe, G. Faa et al., "Rapid multiplex real-time PCR by molecular beacons for different BRAF allele detection in papillary thyroid carcinoma," Diagnostic Molecular Pathology, vol. 19, no. 1, pp. 1-8, 2010.

[36] K. Szuhai, E. Sandhaus, S. M. Kolkman-Uljee et al., "A novel strategy for human papillomavirus detection and genotyping with sybrgreen and molecular beacon polymerase chain reaction," American Journal of Pathology, vol. 159, no. 5, pp. 1651-1660, 2001.

[37] B. A. J. Giesendorf, J. A. M. Vet, S. Tyagi, E. J. M. G. Mensink, F. J. M. Trijbels, and H. J. Blom, "Molecular beacons: a new approach for semiautomated mutation analysis," Clinical Chemistry, vol. 44, no. 3, pp. 482-486, 1998.

[38] K. Frei, K. Szuhai, T. Lucas et al., "Connexin 26 mutations in cases of sensorineural deafness in eastern Austria," European Journal of Human Genetics, vol. 10, no. 7, pp. 427-432, 2002.
[39] D. R. Hodgson, C. A. Foy, M. Partridge, S. Pateromichelakis, and N. J. Gibson, "Development of a facile fluorescent assay for the detection of 80 mutations within the p53 gene," Molecular Medicine, vol. 8, no. 5, pp. 227-237, 2002.

[40] J. B. Biggins, J. R. Prudent, D. J. Marshall, M. Ruppen, and J. S. Thorson, "A continuous assay for DNA cleavage: the application of 'break lights' to enediynes, iron-dependent and nucleases," Proceedings of the National Academy of Sciences of the United States of America, vol. 97, no. 25, pp. 13537-13542, 2000.

[41] J. J. Li, R. Geyer, and W. Tan, "Using molecular beacons as a sensitive fluorescence assay for enzymatic cleavage of singlestranded DNA," Nucleic acids research, vol. 28, no. 11, article e52, 2000.

[42] C. D. Medley, T. J. Drake, J. M. Tomasini, R. J. Rogers, and W. Tan, "Simultaneous monitoring of the expression of multiple genes inside of single breast carcinoma cells," Analytical Chemistry, vol. 77, no. 15, pp. 4713-4718, 2005.

[43] X. H. Peng, Z. H. Cao, J. T. Xia et al., "Real-time detection of gene expression in cancer cells using molecular beacon imaging: new strategies for cancer research," Cancer Research, vol. 65, no. 5, pp. 1909-1917, 2005.

[44] L. Yang, Z. Cao, Y. Lin, W. C. Wood, and C. A. Staley, "Molecular beacon imaging of tumor marker gene expression in pancreatic cancer cells," Cancer Biology and Therapy, vol. 4, no. 5, pp. 561-570, 2005.

[45] A. Wang, A. M. Salazar, M. V. Yates, A. Mulchandani, and W. Chen, "Visualization and detection of infectious coxsackievirus replication using a combined cell culture-molecular beacon assay," Applied and Environmental Microbiology, vol. 71, no. 12, pp. 8397-8401, 2005.

[46] P. Santangelo, N. Nitin, L. LaConte, A. Woolums, and G. Bao, "Live-cell characterization and analysis of a clinical isolate of bovine respiratory syncytial virus, using molecular beacons," Journal of Virology, vol. 80, no. 2, pp. 682-688, 2006.

[47] H. Y. Yeh, M. V. Yates, A. Mulchandani, and W. Chen, "Visualizing the dynamics of viral replication in living cells via Tat peptide delivery of nuclease-resistant molecular beacons," Proceedings of the National Academy of Sciences of the United States of America, vol. 105, no. 45, pp. 17522-17525, 2008.

[48] D. P. Bratu, B. J. Cha, M. M. Mhlanga, F. R. Kramer, and S. Tyagi, "Visualizing the distribution and transport of mRNAs in living cells," Proceedings of the National Academy of Sciences of the United States of America, vol. 100, no. 23, pp. 1330813313, 2003.

[49] D. P. Bratu, "Molecular beacons light the way: imaging native mRNAs in living cells," Discovery Medicine, vol. 3, no. 19, pp. 44-47, 2003.

[50] S. Tyagi and O. Alsmadi, "Imaging native $\beta$-actin mRNA in motile fibroblasts," Biophysical Journal, vol. 87, no. 6, pp. 4153-4162, 2004.

[51] B. Simon, M. Sandhu, and K. L. Myhr, "Live FISH: imaging mRNA in living neurons," Journal of Neuroscience Research, vol. 88, no. 1, pp. 55-63, 2010.

[52] X. Fang, J. J. Li, J. Perlette, W. Tan, and K. Wang, "Molecular beacons: novel fluorescent probes," Analytical Chemistry, vol. 72, no. 23, pp. 747A-753A, 2000.

[53] W. Tan, X. Fang, J. Li, and X. Liu, "Molecular beacons: a novel DNA probe for nucleic acid and protein studies," Chemistry, vol. 6, no. 7, pp. 1107-1111, 2000.

[54] S. A. Marras, F. R. Kramer, and S. Tyagi, "Efficiencies of fluorescence resonance energy transfer and contact-mediated quenching in oligonucleotide probes," Nucleic Acids Research, vol. 30, no. 21, article e122, 2002. 
[55] K. M. Parkhurst and L. J. Parkhurst, "Donor- acceptor distance distributions in a double-labeled fluorescent oligonucleotide both as a single strand and in duplexes," Biochemistry®, vol. 34, no. 1, pp. 293-300, 1995.

[56] S. Bernacchi and Y. Mély, "Exciton interaction in molecular beacons: a sensitive sensor for short range modifications of the nucleic acid structure," Nucleic Acids Research, vol. 29, no. 13, article e62, 2001.

[57] A. Tsourkas, M. A. Behlke, and G. Bao, "Structure-function relationships of shared-stem and conventional molecular beacons," Nucleic Acids Research, vol. 30, no. 19, pp. 42084215, 2002.

[58] E. McGown, M. Su, and R. Dennis, "Measurement of molecular beacons in the SPECTRAmax $(\mathrm{B}$ GEMINI spectrofluorometer," Journal of Chemical Technology and Biotechnology, vol. 75, no. 10, pp. 942-944, 2000.

[59] C. A. M. Seidel, A. Schulz, and M. H. M. Sauer, "Nucleobasespecific quenching of fluorescent dyes. 1. Nucleobase oneelectron redox potentials and their Correlation with static and dynamic quenching efficiencies," Journal of Physical Chemistry, vol. 100, no. 13, pp. 5541-5553, 1996.

[60] T. Heinlein, J. P. Knemeyer, O. Piestert, J. Wolfrum, and M. Sauer, "Nucleobase-specific quenching of fluorescent dyes in DNA-hairpins," The Journal of Physical Chemistry B, vol. 107, no. 31, pp. 7957-7964, 2003.

[61] G. Luo, L. Zheng, X. Zhang, J. Zhang, P. Nilsson-Ehle, and N. $\mathrm{Xu}$, "Genotyping of single nucleotide polymorphisms using base-quenched probe: a method does not invariably depend on the deoxyguanosine nucleotide," Analytical Biochemistry, vol. 386, no. 2, pp. 161-166, 2009.

[62] S. A. Oladepo and G. R. Loppnow, "Self-quenching smart probes as a platform for the detection of sequence-specific UV-induced DNA photodamage," Analytical and Bioanalytical Chemistry, vol. 397, no. 7, pp. 2949-2957, 2010.

[63] N. Venkatesan, Y. J. Seo, and B. H. Kim, "Quencher-free molecular beacons: a new strategy in fluorescence based nucleic acid analysis," Chemical Society Reviews, vol. 37, no. 4, pp. 648-663, 2008.

[64] P. M. Holland, R. D. Abramson, R. Watson, and D. H. Gelfand, "Detection of specific polymerase chain reaction product by utilizing the 5' $\rightarrow$ 3' exonuclease activity of Thermus aquaticus DNA polymerase," Proceedings of the National Academy of Sciences of the United States of America, vol. 88, no. 16, pp. 7276-7280, 1991.

[65] S. Tyagi, S. A. E. Marras, and F. R. Kramer, "Wavelength-shifting molecular beacons," Nature Biotechnology, vol. 18, no. 11, pp. 1191-1196, 2000.

[66] S. Tyagi, D. P. Bratu, and F. R. Kramer, "Multicolor molecular beacons for allele discrimination," Nature Biotechnology, vol. 16, no. 1, pp. 49-53, 1998.

[67] L. Tan, Y. Li, T. J. Drake et al., "Molecular beacons for bioanalytical applications," Analyst, vol. 130, no. 7, pp. 1002-1005, 2005.

[68] M. Zuker, "Mfold web server for nucleic acid folding and hybridization prediction," Nucleic Acids Research, vol. 31, no. 13, pp. 3406-3415, 2003.

[69] J. Perlette and W. Tan, "Real-time monitoring of intracellular mRNA hybridization inside single living cells," Analytical Chemistry, vol. 73, no. 22, pp. 5544-5550, 2001.

[70] J. R. Lakowicz, Principles of Fluorescence Spectroscopy, Springer, New York, NY, USA, 3rd edition, 2006.

[71] C. J. Yang, M. Pinto, K. Schanze, and W. Tan, "Direct synthesis of an oligonucleotide-poly-(phenylene ethynylene) conju- gate with a precise one-to-one molecular ratio," Angewandte Chemie, vol. 44, no. 17, pp. 2572-2576, 2005.

[72] H. Huang, K. Wang, W. Tan et al., "Design of a modularbased fluorescent conjugated polymer for selective sensing," Angewandte Chemie, vol. 43, no. 42, pp. 5635-5638, 2004.

[73] J. J. Li, R. Geyer, and W. Tan, "Using molecular beacons as a sensitive fluorescence assay for enzymatic cleavage of singlestranded DNA," Nucleic Acids Research, vol. 28, no. 11, article e52, 2000.

[74] C. J. Yang, J. J. Li, and W. Tan, "Using molecular beacons for sensitive fluorescence assays of the enzymatic cleavage of nucleic acids," Methods in Molecular Biology, vol. 335, pp. 7181, 2006.

[75] C. J. Yang, C. D. Medley, and W. Tan, "Monitoring nucleic acids using molecular beacons," Current Pharmaceutical Biotechnology, vol. 6, no. 6, pp. 445-452, 2005.

[76] C. Molenaar, S. A. Marras, J. C. Slats et al., "Linear 2' OMethyl RNA probes for the visualization of RNA in living cells," Nucleic Acids Research, vol. 29, no. 17, article e89, 2001.

[77] A. Tsourkas, M. A. Behlke, and G. Bao, "Hybridization of 2'O-methyl and 2-deoxy molecular beacons to RNA and DNA targets," Nucleic Acids Research, vol. 30, no. 23, pp. 51685174, 2002.

[78] R. H. Kehlenbach, "In vitro analysis of nuclear mRNA export using molecular beacons for target detection," Nucleic Acids Research, vol. 31, no. 11, article e64, 2003.

[79] R. Shah and W. S. El-Deiry, "p53-dependent activation of a molecular beacon in tumor cells following exposure to doxorubicin chemotherapy," Cancer Biology and Therapy, vol. 3, no. 9, pp. 871-875, 2004.

[80] V. Vijayanathan, T. Thomas, L. H. Sigal, and T. J. Thomas, "Direct measurement of the association constant of HER2/neu antisense oligonucleotide to its target RNA sequence using a molecular beacon," Antisense and Nucleic Acid Drug Development, vol. 12, no. 4, pp. 225-233, 2002.

[81] K. Petersen, U. Vogel, E. Rockenbauer et al., "Short PNA molecular beacons for real-time PCR allelic discrimination of single nucleotide polymorphisms," Molecular and Cellular Probes, vol. 18, no. 2, pp. 117-122, 2004.

[82] H. Kuhn, V. V. Demidov, B. D. Gildea, M. J. Fiandaca, J. C. Coull, and M. D. Frank-Kamenetskii, "PNA beacons for duplex DNA," Antisense and Nucleic Acid Drug Development, vol. 11, no. 4, pp. 265-270, 2001.

[83] C. J. Yang, L. Wang, Y. Wu et al., "Synthesis and investigation of deoxyribonucleic acid/locked nucleic acid chimeric molecular beacons," Nucleic Acids Research, vol. 35, no. 12, pp. 4030-4041, 2007.

[84] X. Fang, J. J. Li, and W. Tan, "Using molecular beacons to probe molecular interactions between lactate dehydrogenase and single-stranded DNA," Analytical Chemistry, vol. 72, no. 14, pp. 3280-3285, 2000.

[85] R. Yang, J. Jin, Y. Chen et al., "Carbon nanotube-quenched fluorescent oligonucleotides: probes that fluoresce upon hybridization," Journal of the American Chemical Society, vol. 130, no. 26, pp. 8351-8358, 2008.

[86] N. Graf, M. Göritz, and R. Krämer, "A metal-ion-releasing probe for DNA detection by catalytic signal amplification," Angewandte Chemie, vol. 45, no. 24, pp. 4013-4015, 2006.

[87] A. K. Chen, M. A. Behlke, and A. Tsourkas, "Sub-cellular trafficking and functionality of 2 -O-methyl and 2 -Omethyl-phosphorothioate molecular beacons," Nucleic Acids Research, vol. 37, no. 22, article e149, 2009. 
[88] W. J. Rhee and G. Bao, "Slow non-specific accumulation of 2'-deoxy and 2'-O-methyl oligonucleotide probes at mitochondria in live cells," Nucleic Acids Research, vol. 38, no. 9, article e109, 2010.

[89] A. K. Chen, M. A. Behlke, and A. Tsourkas, "Avoiding falsepositive signals with nuclease-vulnerable molecular beacons in single living cells," Nucleic Acids Research, vol. 35, no. 16, article e105, 2007.

[90] Y. Wu, C. J. Yang, L. L. Moroz, and W. Tan, "Nucleic acid beacons for long-term real-time intracellular monitoring," Analytical Chemistry, vol. 80, no. 8, pp. 3025-3028, 2008.

[91] Y. Kim, C. J. Yang, and W. Tan, "Superior structure stability and selectivity of hairpin nucleic acid probes with an L-DNA stem," Nucleic Acids Research, vol. 35, no. 21, pp. 7279-7287, 2007.

[92] R. W. Dirks, C. Molenaar, and H. J. Tanke, "Visualizing RNA molecules inside the nucleus of living cells," Methods, vol. 29, no. 1, pp. 51-57, 2003.

[93] M. A. Barry and A. Eastman, "Identification of deoxyribonuclease II as an endonuclease involved in apoptosis," Archives of Biochemistry and Biophysics, vol. 300, no. 1, pp. 440-450, 1993.

[94] R. V. Giles, C. J. Ruddell, D. G. Spiller, J. A. Green, and D. M. Tidd, "Single base discrimination for ribonuclease $\mathrm{H}$ dependent antisense effects within intact human leukaemia cells," Nucleic Acids Research, vol. 23, no. 6, pp. 954-961, 1995.

[95] R. V. Giles, D. G. Spiller, J. Grzybowski, R. E. Clark, P. Nicklin, and D. M. Tidd, "Selecting optimal oligonucleotide composition for maximal antisense effect following streptolysin Omediated delivery into human leukaemia cells," Nucleic Acids Research, vol. 26, no. 7, pp. 1567-1575, 1998.

[96] I. Walev, S. C. Bhakdi, F. Hofmann et al., "Delivery of proteins into living cells by reversible membrane permeabilization with streptolysin-O," Proceedings of the National Academy of Sciences of the United States of America, vol. 98, no. 6, pp. 3185-3190, 2001.

[97] M. Becker-Hapak, S. S. McAllister, and S. F. Dowdy, "TATmediated protein transduction into mammalian cells," Methods, vol. 24, no. 3, pp. 247-256, 2001.

[98] E. L. Snyder and S. F. Dowdy, "Protein/peptide transduction domains: potential to deliver large DNA molecules into cells," Current Opinion in Molecular Therapeutics, vol. 3, no. 2, pp. 147-152, 2001.

[99] J. S. Wadia and S. F. Dowdy, "Protein transduction technology," Current Opinion in Biotechnology, vol. 13, no. 1, pp. 52$56,2002$.

[100] H. Brooks, B. Lebleu, and E. Vivès, "Tat peptide-mediated cellular delivery: back to basics," Advanced Drug Delivery Reviews, vol. 57, no. 4, pp. 559-577, 2005.

[101] J. S. Wadia and S. F. Dowdy, "Transmembrane delivery of protein and peptide drugs by TAT-mediated transduction in the treatment of cancer," Advanced Drug Delivery Reviews, vol. 57, no. 4, pp. 579-596, 2005.

[102] N. Nitin, P. J. Santangelo, G. Kim, S. Nie, and G. Bao, "Peptide-linked molecular beacons for efficient delivery and rapid mRNA detection in living cells," Nucleic Acids Research, vol. 32, no. 6, article e58, 2004.

[103] N. Nitin and G. Bao, "NLS peptide conjugated molecular beacons for visualizing nuclear RNA in living cells," Bioconjugate Chemistry, vol. 19, no. 11, pp. 2205-2211, 2008.

[104] A. K. Chen, M. A. Behlke, and A. Tsourkas, "Efficient cytosolic delivery of molecular beacon conjugates and flow cytometric analysis of target RNA," Nucleic Acids Research, vol. 36, no. 12, article e69, 2008.

[105] T. M. Klein, E. D. Wolf, R. Wu, and J. C. Sanford, "High-velocity microprojectiles for delivering nucleic acids into living cells," Nature, vol. 327, no. 6117, pp. 70-73, 1987.

[106] N. S. Yang, J. Burkholder, B. Roberts, B. Martinell, and D. McCabe, "In vivo and in vitro gene transfer to mammalian somatic cells by particle bombardment," Proceedings of the National Academy of Sciences of the United States of America, vol. 87, no. 24, pp. 9568-9572, 1990.

[107] E. F. Fynan, R. G. Webster, D. H. Fuller, J. R. Haynes, J. C. Santoro, and H. L. Robinson, "DNA vaccines: protective immunizations by parenteral, mucosal, and gene- gun inoculations," Proceedings of the National Academy of Sciences of the United States of America, vol. 90, no. 24, pp. 11478-11482, 1993.

[108] J. A. Wolff, P. Williams, G. Acsadi, S. Jiao, A. Jani, and W. Chong, "Conditions affecting direct gene transfer into rodent muscle in vivo," BioTechniques, vol. 11, no. 4, pp. 474-485, 1991.

[109] C. Condon, S. C. Watkins, C. M. Celluzzi, K. Thompson, and L. D. Falo, "DNA-based immunization by in vivo transfection of dendritic cells," Nature Medicine, vol. 2, no. 10, pp. 11221128, 1996.

[110] D. H. Mathews, J. Sabina, M. Zuker, and D. H. Turner, "Expanded sequence dependence of thermodynamic parameters improves prediction of RNA secondary structure," Journal of Molecular Biology, vol. 288, no. 5, pp. 911-940, 1999.

[111] S. F. Altschul, W. Gish, W. Miller, E. W. Myers, and D. J. Lipman, "Basic local alignment search tool," Journal of Molecular Biology, vol. 215, no. 3, pp. 403-410, 1990.

[112] P. J. Santangelo, B. Nix, A. Tsourkas, and G. Bao, "Dual FRET molecular beacons for mRNA detection in living cells," $\mathrm{Nu}$ cleic Acids Research, vol. 32, no. 6, article e57, 2004.

[113] A. Tsourkas, M. A. Behlke, Y. Xu, and G. Bao, "Spectroscopic features of dual fluorescence/luminescence resonance energy-transfer molecular beacons," Analytical Chemistry, vol. 75, no. 15, pp. 3697-3703, 2003.

[114] K. Wang, Z. Tang, C. J. Yang et al., "Molecular engineering of DNA: molecular beacons," Angewandte Chemie, vol. 48, no. 5, pp. 856-870, 2009.

[115] T. J. Drake, C. D. Medley, A. Sen, R. J. Rogers, and W. Tan, "Stochasticity of manganese superoxide dismutase mRNA expression in breast carcinoma cells by molecular beacon imaging," ChemBioChem, vol. 6, no. 11, pp. 2041-2047, 2005.

[116] H. Y. Yeh, M. V. Yates, A. Mulchandani, and W. Chen, "Visualizing the dynamics of viral replication in living cells via Tat peptide delivery of nuclease-resistant molecular beacons," Proceedings of the National Academy of Sciences of the United States of America, vol. 105, no. 45, pp. 17522-17525, 2008. 

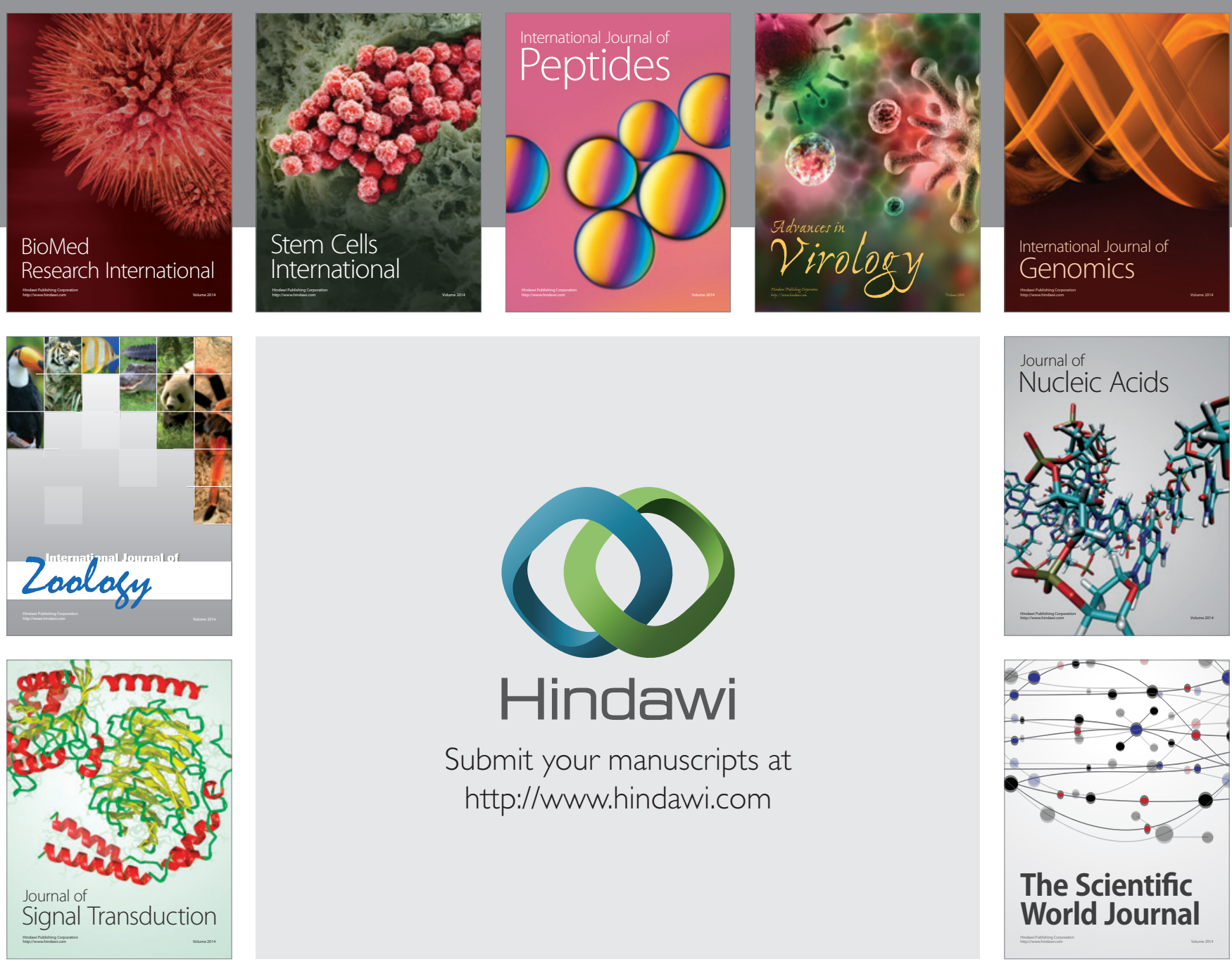

Submit your manuscripts at

http://www.hindawi.com
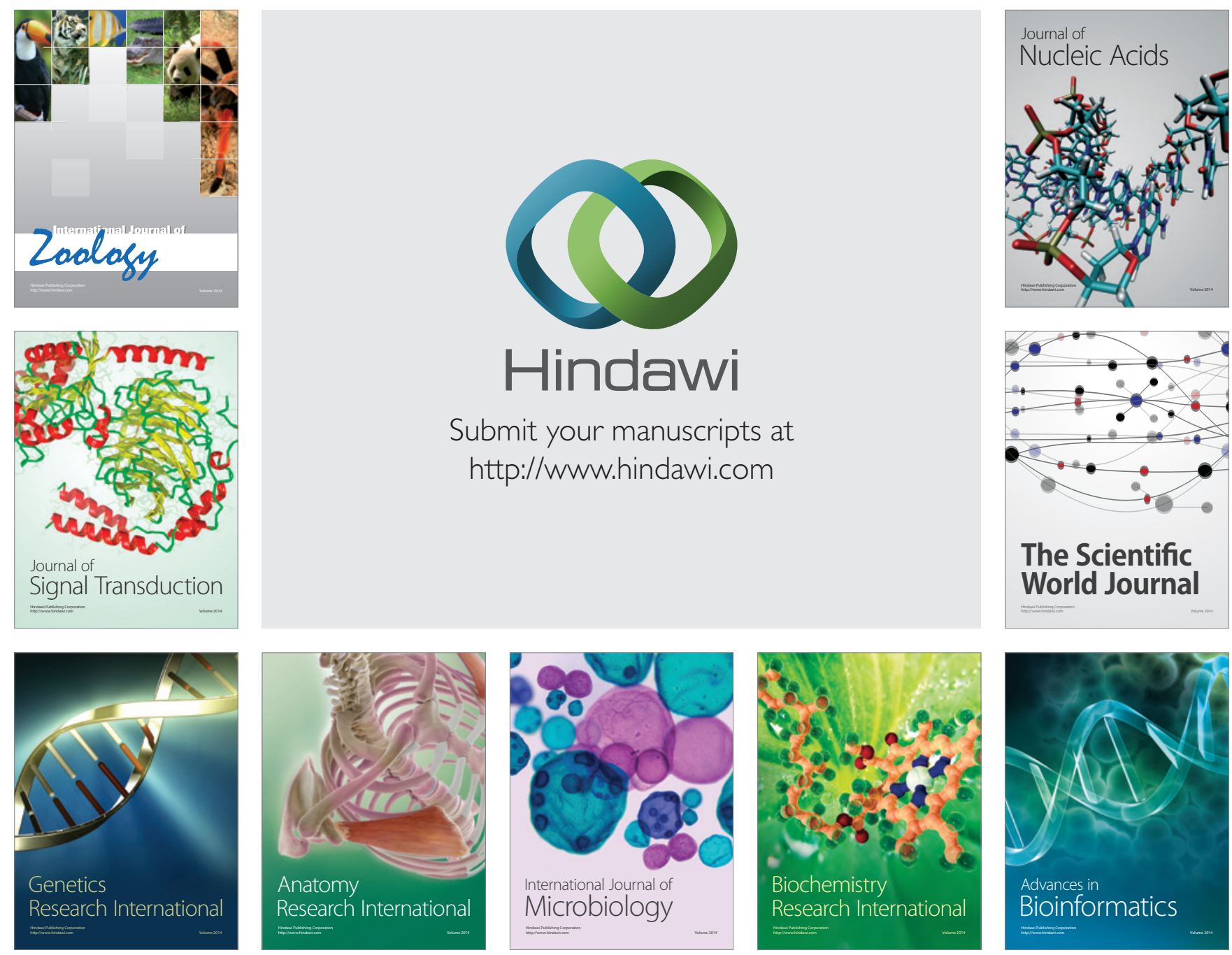

The Scientific World Journal
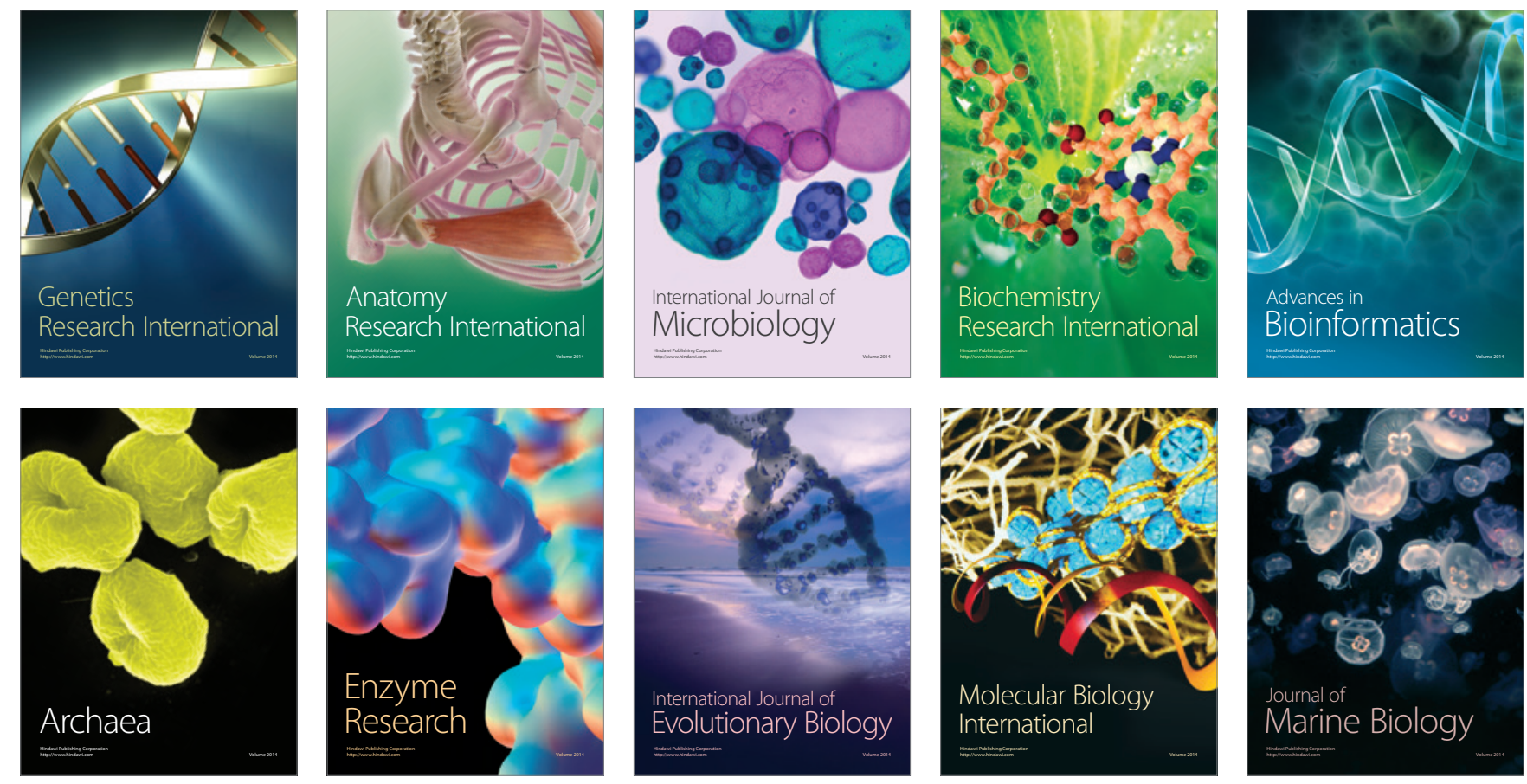